\title{
Identification of Markers Linked to a Celery Mosaic Virus Resistance Gene in Celery
}

\author{
Juan J. Ruiz, ${ }^{1}$ Belen Pico, ${ }^{2}$ Genyi Li, Vincent D'Antonio, Bryce Falk, ${ }^{3}$ and Carlos F. Quiros ${ }^{4}$ \\ Department of Vegetable Crops, University. of California, Davis, CA 95616
}

\begin{abstract}
AdDitional INDEX wORDs. virus resistance, molecular markers, DNA, mapping, gene tagging, marker assisted selection
Abstract. Resistance to Celery mosaic virus (CeMV) in celery [Apium graveolens L. var. dulce (Mill.) Pers.] is recessive and determined by the single gene, $c m v$. We report discovery of two polymerase chain reaction-based dominant markers tightly linked to $\mathrm{cm} v$ in segregating $\mathrm{F}_{2}$ and $\mathrm{BC}_{1}$ populations. Marker me1em2 is associated to the dominant (susceptibility allele) and the second marker, me8em2, to the recessive (resistance allele). Simultaneous screening for both markers in segregating populations allows for identification of both homozygous and heterozygous genotypes for disease resistance. This marker system can be used for early seedling selection, which will simplify and speed development of celery cultivars resistant to CeMV.
\end{abstract}

Celery mosaic virus (CeMV) is the most common virus affecting celery (Apium graveolens var dulce), which is the primary host of this pathogen. CeMV is an important aphid [(Myzus persicae (Sulz.)] transmitted virus of celery and also infects related crops, like carrot (Daucus carota L.), parsley [Petroselinum crispum (Mill.) Nyman ex A. w. Hill], parsnip (Pastinaca sativa L.), coriander (Coriandrum sativum L.), and dill (Anethum graveolens L.). This virus has also been known as apium virus 1 , celery western mosaic virus, and celery ringspot virus (Hollings, 1964; Pemberton and Frost, 1986).

Disease symptoms caused by CeMV include yellowing of foliage, mosaic and/or mottling patterns on leaves, vein clearing, and curled, crinkled, or otherwise distorted foliage. Plants are sometimes stunted. Outer petioles grow horizontally, giving the plant a flattened appearance. Certain strains of CeMV may cause more severe symptoms than others.

$\mathrm{CeMV}$ is probably distributed worldwide. In the United States, it is present in the western states and Florida. CeMV was first reported in celery in California, in 1938 (Brunt et al., 1997). A host-free period of at least 2 to 3 months, in which celery is not being grown in the area, greatly reduces the incidence of celery mosaic in California and Australia. In areas where other host crops for CeMV, such as carrot, parsley, and coriander are produced year-round in the same district, these may act as sources of inoculum making control of this disease very complex. Also, the presence of host weeds in celery production areas makes impractical application of celery-free periods as a measure to control this disease (Brunt et al., 1997). This is the case in the United Kingdom where the virus infects wild hemlock (Cicuta virosa $\mathrm{L}$.) and other weeds (Walkey et al., 1970).

Although the celery-free period or fallow break could be enough in most situations to combat CeMV, development of resistant cultivars is usually the best agronomic solution.

Received for publication 24 Oct. 2000. Accepted for publication 13 Mar. 2001. This work was supported by a grant to C.F.Q. by the California Celery Research Advisory Board. Juan J. Ruiz and Belen Pico acknowledge financial support of the Generalitat Valenciana during their stay at UC-Davis. We are indebted to Roger Chetelat and Sylvaine Coulibaly for critical reading of the manuscript. The cost of publishing this paper was defrayed in part by the payment of page charges. Under postal regulations, this paper therefore must be hereby marked advertisement solely to indicate this fact. ${ }^{1}$ Present address: Department of Applied Biology, Universidad. Miguel Hernandez, Orihuela (Alicante) 03312, Spain.

${ }^{2}$ Present address: Department of Biotechnology, Universidad. Politecnica de Valencia, Valencia 46022, Spain.

${ }^{3}$ Department of Plant Pathology.

${ }^{4}$ Corresponding author; e-mail: cfquiros@ucdavis.edu.
D'Antonio et al. (unpublished data) have recently identified a resistant feral accession of celery. The resistance is recessive and determined by a single gene, $\mathrm{cm} v$. To accelerate introgression of this resistance into cultivated lines, it would be desirable to have molecular markers to better perform selection of this recessive allele. In this paper, we report discovery of two polymerase chain reaction (PCR)-based markers tightly linked to gene, $c m v$, which may be used in celery breeding programs.

\section{Materials and Methods}

Plant material. A $100 \mathrm{~F}_{2}$ plant population segregating for the resistance gene, $c m v$, derived from the cross hybridization between the resistant feral celery accession A69 collected from Oso Flaco, Calif., and the cultivar Promise (susceptible) was used. In addition, a 48-plant population (22 resistant/26 susceptible) originating from the backcross to the susceptible parent confirmed the linkage between the markers and the resistance gene. Eightweek-old seedlings were inoculated with an extract of leaves from CeMV-infested plants. The inoculum was prepared by crushing three young leaves in a mortar and pestle in $10 \mathrm{~mL}$ of $0.03 \mathrm{~mol} \cdot \mathrm{L}^{-1}$ potassium phosphate buffer and $0.1 \%$ sodium sulfite, $\mathrm{pH}$ 7.0. The leaves of the healthy plants were rubbed with the wet pestle using Celite (Fisher, Pittsburg, Pa.) as an abrasive. About 50 plants were inoculated with $10 \mathrm{~mL}$ of the virus suspension solution. The first reading was taken after 3 weeks and then each week thereafter for a total of seven readings. The plants were scored on a scale of 1 to 5,1 being free of symptoms and 5 being most severe symptom expression. Readings were taken on the youngest leaves. Only plants with a score of 1 were considered resistant.

DNa EXTRaCtion. A modified version of the cetyltrimethylammonium bromide (CTAB) method was used to extract genomic DNA (Yang and Quiros, 1995a). A $1.5 \mathrm{~mL}$ eppendorf tube containing $\approx 0.3 \mathrm{~g}$ of fresh leaf tissue was placed into liquid nitrogen for $30 \mathrm{~s}$ and its contents crushed with a small plastic bar. A volume of $0.5 \mathrm{~mL} 2 \times \mathrm{CTAB}$ buffer was added to the tubes and incubated at $65^{\circ} \mathrm{C}$ for $90 \mathrm{~min}$. After incubation, $0.4 \mathrm{~mL}$ chloroform was added and the tubes were centrifuged at $14,000 g_{n}$ for 3 min. The supernatant was transferred into a new tube and the DNA precipitated in a 0.5 volume of 2-propanol. The DNA was then washed with $70 \%$ ethanol and dissolved in TE buffer.

GENE TAGGING WITH PCR MARKERS. We used sequence related amplified markers (SRAPs) (Li and Quiros, 2001), which are PCR-based markers amplified by two primers, a forward primer 
Table 1. List of primers used for amplifying genomic DNA of celery plants segregating for CeMV resistance.

\begin{tabular}{l} 
Forward primers \\
\hline me1, 5'-TGAGTCCAAACCGGATA-3' \\
me2, 5'-TGAGTCCAAACCGGAGC-3' \\
me3, 5'-TGAGCTCAAACCGGAAT-3' \\
me4, 5'-TGAGCTCAAACCGGACC-3' \\
me5, 5'-TGAGTCCAAACCGGAAG-3' \\
me6, 5'-TGAGCTCTTTCCGGTAA-3' \\
me7, 5'-TGAGCTCTTTCCGGTCC-3' \\
me8, 5'-TGAGTCCTTTCCGGTGC-3' \\
me9, 5'-ACAGTCGAAACCGGAAT-3' \\
me10, 5'-ACAGTGGAAACGCGAAC-3'
\end{tabular}

of 17 bases and reverse primer of 18 bases. These are labelled with $\left[\mathrm{g}^{33} \mathrm{P}\right]$ for amplification of genomic DNA. The sets of primers used are listed in Table 1.

DNA AMPLifiCATION. At the beginning of the PCR reaction, the annealing temperature was set at $35^{\circ} \mathrm{C}$ and run for 5 cycles. Then the annealing temperature was raised to $50{ }^{\circ} \mathrm{C}$ for another 35 cycles. Denaturing was done at $94{ }^{\circ} \mathrm{C}$ for $1 \mathrm{~min}$, while extension was carried out at $72{ }^{\circ} \mathrm{C}$ for $1 \mathrm{~min}$ in all cycles. The amplified bands were separated by denaturing acrylamide sequencing gels and detected by autoradiography (Li and Quiros, 2001).

IDENTIFICATION OF SRAP MARKERS LINKED TO THE RESISTANCE GENE. A total of 26 primer combinations were screened to identify polymorphic SRAP markers between resistant and susceptible plants. Instead of using a bulk segregant analysis strategy, we compared for each primer combination, four resistant plants with four susceptible plants from the $\mathrm{F}_{2}$ population. In this fashion, six different combinations of primers could be run in a single gel of 48 wells. By using this strategy, we were able to detect markers linked both in repulsion phase and in coupling phase to the resistance gene. If we had pooled the DNA in two bulks, resistant and susceptible, we would not have been able to detect markers linked in coupling phase. Because a recessive allele determines resistance, the susceptible bulk (dominant allele) would comprise both homozygous and heterozygous individuals, so a marker linked to the recessive resistant allele will not show polymorphism between the two bulks. Putative markers selected by this approach were then screened in the whole population.

SEQUENCING OF SRAP MARKER BANDS. After electrophoresis, the gel was exposed overnight to a high sensitivity film (BioMax, Eastman Kodak, Rochester, N.Y.). Using the exposed film as a blueprint, the gel pieces containing the polymorphic bands were cut and introduced into a dialysis tube. The tube was placed into the buffer tank of a sequencing gel apparatus (FB-SEQ 3545; Fisher, Pittsburg, Pa.), and the DNA was electroeluted in $1 \times$ TBE buffer at $2000 \mathrm{~V}$. The solution from the dialysis tube was transferred into a $1.5 \mathrm{~mL}$ tube, extracted with an equal volume of phenol:chloroform (v/v), mixed, and centrifuged at $14,000 g_{\mathrm{n}}$ for $5 \mathrm{~min}$. The supernatant was transferred into a new $1.5 \mathrm{~mL}$ tube and $1 \mathrm{~mL}$ ethanol $(\mathrm{EtOH})$ acetate mix was added. The tube was inverted gently and centrifuged at $14,000 g_{\mathrm{n}}$ for $5 \mathrm{~min}$, after which the supernatant was discarded. The DNA was washed in $70 \% \mathrm{EtOH}$, dried and resuspended in $30 \mathrm{~mL}$ sterile distilled water before quantification on agarose gels with DNA concentration standards.

\section{Results and Discussion}

Polymorphism. The level of polymorphism observed in the plants of the segregating $\mathrm{F}_{2}$ population was rather low; only 89 of
Reverse primers

em1, 5'-GACTGCGTACGAATTCAA-3' em2, 5'-GACTGCGTACGAATTCTG-3' em3, 5'-GACTGCGTACGAATTCGA-3' em4, 5'-GACTGCGTACGAATTCTG-3' em5, 5'-GACTGCGTACGAATTCAA-3' em6, 5'-GACTGCGTACGAATTCCA-3'
A

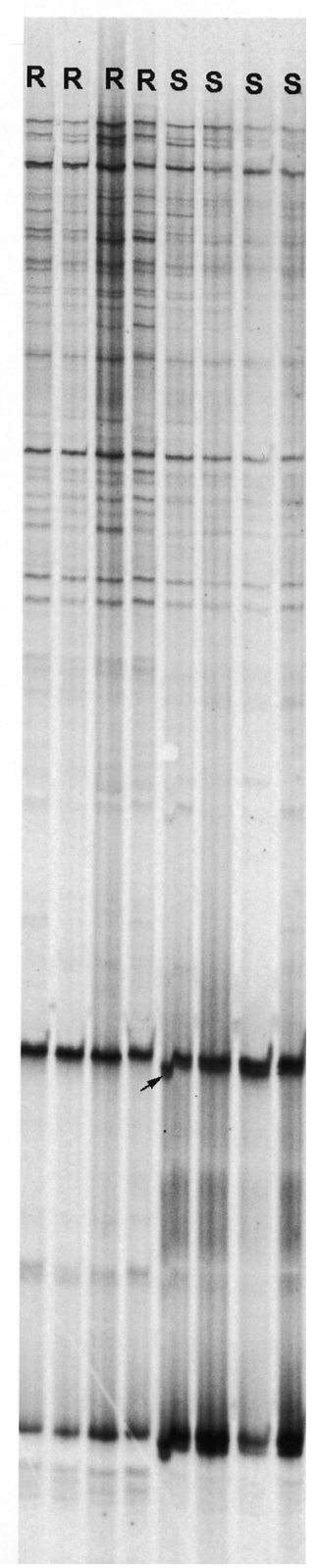

the 572 bands $(15.5 \%)$ obtained with the 26 primer combinations were polymorphic between the susceptible and resistant plants. The reason for this low level of polymorphism is probably the genetic similarity between the cultivar and the source of resistance, a feral or weedy accession. This is not a surprising result, considering that celery was introduced from France to North America in 1887 (Vilmorin, 1950), so the level of divergence that can be expected in a plant escaped from cultivation is very low.

SRAP MARKERS. Among the 89 polymorphic bands, we found two markers tightly linked to the resistance gene, one of them linked in coupling phase and the other linked in repulsion phase. Because a

Fig. 1. Marker detected by the primer combination me1-em2. (A) Complete profile of bands amplified by the me1-em2 primers for a test run of four resistant (R) and four susceptible $(S) F_{2}$ plants is illustrated. Only the susceptible plants show a doublet of bands (arrow), whereas the resistant plants show instead a single band $(185 \mathrm{bp})$ in the same area of the gel. The 185 bp band is monomorphic, since it is present in all plants, whereas the lower band (184 bp) forming the doublet with the 185 bp band, is only present in the susceptible plants. Note the smaller bands at the lower part of the gel reflecting the same pattern of the informative $185 / 184 \mathrm{bp}$ melem 2 bands. These share the same sequences but because of their small size their resolution tend to be poor. (B) Sample of cosegregating plants for resistance and for the melem 2 marker. The marker was present in all 78 susceptible plants, and it was absent in all 22 resistant plants.
B

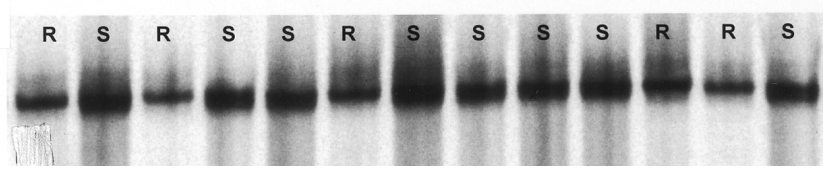


higher number of loci would normally be required to find linked markers (Tanksley et al., 1995), this is an unexpectedly high rate of success, and is only due partially to chance. The SRAP system, with the sequence CCGG in the forward primers and the sequence AATT in the reverse primers, was designed to target open reading frames (Li and Quiros, 2001). When this marker technique was tested in a series of recombinant inbreds and doubled-haploid lines of Brassica oleracea L., $\approx 45 \%$ of sequence gel-isolated bands matched known genes in the Genbank database ( $\mathrm{Li}$ and Quiros, 2001). In addition, by comparison with amplified fragment length polymorphisms (AFLPs), it has been demonstrated that SRAP markers have good coverage of the genome ( $\mathrm{Li}$ and Quiros, 2000). Therefore, it is not so surprising that a marker system, which targets mainly coding genes and has good coverage of the genome was able to rapidly detect markers linked to the resistance gene. Interestingly, this task was successful in celery in spite of the fact that it is a species with a large genome $(6 \mathrm{pg} / 2 \mathrm{C}$, Yang and Quiros 1995a), and considering also that the weedy accession and the cultivated celery probably differ in just a few genes.

MARKER LINKED IN REPULSION PHASE. The primer combination me1-em2 (Table 1) detected a band polymorphic between the four resistant plants and the four susceptible plants selected from the $\mathrm{F}_{2}$ population segregating for CeMV resistance (Fig. 1A). According to its position in the gel, the size of the band was $\approx 200$ base pairs (bp), and it migrated in the gel very close to a second band, that was monomorphic (Fig. 1). The putative marker (lower band) was tested in the $100 \mathrm{~F}_{2}$ plants segregating for CeMV resistance (Fig. 1B). The marker (melem2, hereafter) cosegregated with the susceptible phenotype, with no recombinants, since the lower band was present in all the 78 susceptible plants, and absent in the 22 resistant plants (Fig. 1B). In addition, this marker also cosegregated with disease reaction in the same fashion when the linkage was further tested in the $48 \mathrm{BC} 1$ plants. The band was present in the 26 susceptible plants and absent in the 22 resistant ones. These results indicated a tight linkage between the marker melem 2 and the dominant susceptibility allele. The sequence of the monomorphic band that migrated in the gel close to the polymorphic band was easily obtained by direct sequencing, cutting the band directly out of the gel from the lanes corresponding to resistant plants (single band). The melem 2 polymorphic band, however, which only appeared in the susceptible plants, was not well enough separated from the monomorphic band to be easily excised. In order to sequence this band, products of PCR amplifications corresponding to susceptible plants were run in a gel with higher acrylamide concentration for $4 \mathrm{~h}$, twice the normal running time. In this fashion, the two bands could be separated,

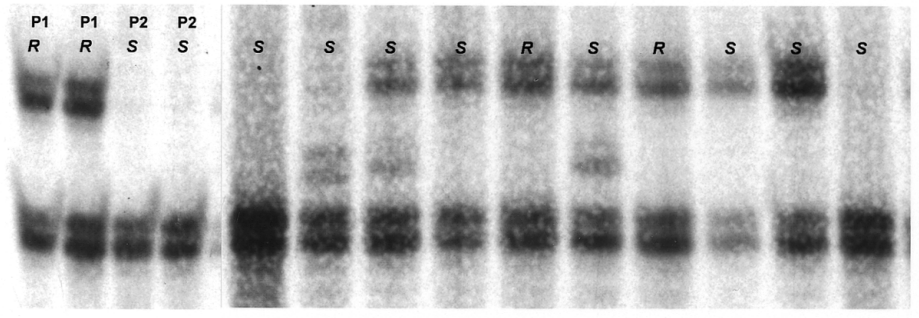

Fig. 2. Marker detected by the primer combination me8-em2. Polymorphism between parental lines (P1, resistant accession A69, and P2, susceptible 'Promise') and sample of derived F2 progeny. The polymorphism consists in two closely migrating bands of 78 and $76 \mathrm{bp}$, which appear in resistant and susceptible heterozygous plants carrying the recessive resistance allele (upper double bands in the photograph). so direct cutting and sequencing was also achieved for the segregating band. The size of the bands differed only in $1 \mathrm{bp}$, the monomorphic band being $185 \mathrm{bp}$ long and the polymorphic band $184 \mathrm{bp}$. Their sequences showed $95 \%$ similarity. As the guanine and cytosine (GC) content of the sequences was low $(<30 \%)$, it was difficult to design primers in order to obtain a codominant marker for the resistance gene. It seems that the large genome of celery contains a high proportion of repetitive DNA, where regions with low GC content are frequent, which is a hindrance for single/low copy marker development (Li and Quiros, 2001). Sequence analysis revealed the presence of a single Alu I restriction site (AGCT) in the monomorphic band and two restriction sites for the same enzyme in the polymorphic band. This difference was confirmed by Alu I digestion of the amplicons from susceptible and resistant plants, and followed by agarose electrophoresis. However, the small size of the resulting bands made it difficult to distinguish those from resistant and susceptible plants. After similarity search in the Genbank database, the sequence of the polymorphic band showed $65 \%$ identity in a 146 nucleotide overlap with an intron of a transporter-like protein gene located on chromosome 3 of Arabidopsis thaliana (L.) Heynh. (accession AL358732, BAC clone T27I15).

MARKER LINKED IN COUPLING PHASE. The primer combination me8-em2 detected two close-migrating concomitant polymorphic bands between the resistant and susceptible plants (Fig. 2). This double-banded marker was designated me8em2. The two polymorphic bands appeared in all 22 resistant plants of the $\mathrm{F}_{2}$ population. They were also present in 57 of the 78 susceptible $F_{2}$ plants (Fig. 2). This proportion fits the expected 2:1 ratio of heterozygous and homozygous susceptible individuals $\left(x^{2}=1.44\right)$. As expected, the band was present in all 48 plants of the $\mathrm{BC}_{1}$ population, which is composed by $50 \%$ heterozygous susceptible individuals and $50 \%$ homozygous resistant (double recessive) individuals. According to the position of the bands in the gel, their sizes were estimated to be $<100 \mathrm{bp}$. Sequencing of the two bands disclosed they differed only by $2 \mathrm{bp}$, the upper band having $78 \mathrm{bp}$ and the lower band $76 \mathrm{bp}$. Their sequences showed $91 \%$ identity and a high GC content $(\approx 48 \%)$, which suggested the primers might have targeted an exon in an open reading frame. After search in Genbank, we found that the lower band showed $72 \%$ identity in a 50 nucleotide overlap with a putative calciumdependent protein kinase located on chromosome 1 of Arabidopsis thaliana (accession AC007396, BAC T4012). An estimated 1\% to $3 \%$ of functional eukaryotic genes encode protein kinases, suggesting they are involved in many aspects of cellular regulation and metabolism (Stone and Walker, 1995), including responses to various signals, such as pathogen invasion. So far, only a few clusters of resistance genes have been sequenced (Michelmore, 2000), but some of them encode protein kinases. Given the high number of protein kinase genes that can be found in eukaryotic organisms and in plants in particular, the probability that the marker we have found had amplified part of a resistance gene is not very high. However, this possibility deserves consideration, taking into account that the weedy accession of celery and the cultivar Promise should not differ in many genes (Orton and Arus, 1982). Further investigation of this interesting issue is hampered by lack of genomic libraries in celery, as well as the sparse nature of its molecular map (Yang and Quiros, 1995b).

Practical utility OF THE Markers. The markers me $1 \mathrm{em} 2$ and $m e 8 e m 2$ found associated with the locus $\mathrm{cmv}$ can be used readily for marker assisted selection, helping to introgress the recessive resistance allele of this gene into cultivated lines. Although these 
are not codominant markers, the linkage in coupling phase of me8em 2 and in repulsion phase of marker melem 2 to the resistance allele, makes it possible to identify all CeMV genotypes. Use of these markers might circumvent in many cases progeny testing of resistant plants, thereby reducing in half the time required to develop CeMV resistant lines.

\section{Conclusion}

Several molecular techniques have been used to identify molecular markers of utility in plant breeding. Each method has its advantages and disadvantages: randomly amplified polymorphic DNA is a simple method, but its poor reproducibility and low multiplexing output limit its use; single sequence repeats has the advantage of mostly codominant markers, but its development is expensive and time consuming; AFLPs have a high multiplexing ratio, but is complex and frequent band overlapping makes band DNA isolation difficult. However, the SRAP protocol combines simplicity, reliability, moderate multiplexing and facile sequencing of selected bands. As a result, we quickly identified SRAP markers linked to the CeMV resistance gene in celery. These markers will be useful for celery breeding, a species lacking a well-developed molecular map. This is the first report of a potentially useful gene tagging in celery.

\section{Literature Cited}

Brunt, A.A., K. Crabtree, M.J. Dallwitz, A.J. Gibss, L. Watson, and E.J. Zurcher.1997. Plant viruses online: Descriptions and list from the
VIDEdatabase. Version: 16 Jan. 1997.URL: http://biology.anu.edu.au/ groups/mes/vide.

Hollings, M. 1964. Some properties of five viruses of celery (Apium graveolens L.) in Britain J. Hort. Sci. 39:130-141.

Li, G. and C.F. Quiros. 2000. Use of amplified fragment length polymorphism markers for celery cultivar identification. HortScience 35:726728.

Li, G. and C.F. Quiros, 2001. Sequence-related amplified polymorphism (SRAP), a new marker system based on a simple PCR reaction: its application to mapping and gene tagging in Brassica. Theor. Appl. Genet. (in press).

Michelmore, R.W. 2000. Genomic approaches to plant disease resistance. Current Opinion in Plant Biol. 3:125-131.

Orton, T.J. and P. Arus. 1982. Genetic studies in wild populations of wild celery in Calfornia. Ann. Bot. 49:461-468.

Pemberton, A.W. and R.R. Frost. 1986. Celery mosaic virus in England. Plant Pathol. 23:20.

Stone, J.M. and C. Walker. 1995. Plant protein kinase families and signal transduction. Plant Physiol. 108:451-457.

Tanksley, S.D., M.W. Ganal, and G.B. Martin. 1995. Chromosome landing: A paradigm for map-based cloning in plants with large genomes. Trends Genet. 11:63-68.

Vilmorin, R.L. 1950. Pascal celery and its origin. J. New York Bot. Garden 51:39-41.

Walkey, D.G.A., J.A. Tomlinson, and J.A. Frowd. 1970. Occurrence of western celery mosaic virus in umbelliferus crops in Britain. Plant Dis. Rpt. 53:370-371.

Yang, X. and C.F. Quiros. 1995a. Characterizing the celery genome with DNA-based genetic markers. J. Amer. Soc. Hort. Sci. 120:747-751.

Yang, X. and C.F. Quiros. 1995b. Construction of a genetic linkage map in celery using DNA-based markers. Genome 28:36-44. 